\title{
MONOGRÁFICO \\ SENTIMIENTO Y RAZÓN: \\ LA POESÍA EN LOS UMBRALES DEL SIGLO ILUSTRADO
}

\author{
Coordinado por \\ Jean-Marc Buigues \\ (Université Bordeaux Montaigne) \\ y Rodrigo Olay Valdés \\ (Universidad de Oviedo)
}


El presente monográfico muestra resultados del proyecto de investigación Poesía hispánica en el bajo barroco (repertorio, edición, historia), FFI2011-24102 del Plan Nacional de Investigación Científica, Desarrollo e Innovación Tecnológica. Al mismo tiempo, avanza en la línea de trabajo planteada en el proyecto Sujeto e institución literaria en la edad moderna, FFI2014-54367-C2-1-R. 
Nota preliminar

\author{
Jean-Marc Buiguès \\ Rodrigo Olay Valdés
}



Por más que juicios como los del marqués de Valmar sancionasen la poesía del bajo Barroco — «Barroco degenerado» durante tanto tiempo- como un «enredado y monótono laberinto de ridículos conceptos, de narraciones chocarreras, de monstruosas hipérboles, de agudezas sin intención ni alcance moral, de alambicamientos peregrinos», una ya larga serie de trabajos ha venido poniendo de manifiesto lo que de renovador alentaba en las prácticas poéticas de las postrimerías del siglo XVII y los albores del XVIII. Tras el pionero simposio «Del Barroco a la Ilustración», celebrado en Montreal en 1996, y luego publicado como anejo de Dieciocho, los trabajos fundamentales de Jesús Pérez Magallón, Alain Bègue y, en especial, Pedro Ruiz Pérez han mirado desde la otra ladera — la de principios de siglo — el proceso que, desde el prisma de los años 40 o 50 del setecientos, atendieron en su día estudiosos como Joaquín Arce, José Miguel Caso González, Nigel Glendinning, Nicolás Marín o Russell P. Sebold. Así, toda una serie de recientes monográficos centrados en el particular, como los de las revistas Criticón, 103-104 (2008) y 119 (2013), Bulletin Hispanique, 113.1 (2011) y 115.1 (2013), Calíope, 18 (2012), Edad de Oro, 31 (2012) o Versants, 60.1 (2013), o, entre otros, los volúmenes colectivos Tras el canon. La poesía del Barroco tardio, en edición de Ignacio García Aguilar (2009), y La luz de la razón. Literatura y Cultura del siglo XVIII (2010), coordinado por Aurora Egido y José Enrique Laplana, han venido jalonando la renovación y puesta al día de todo un siglo de la literatura española (1650-1750).

Este monográfico, «Sentimiento y razón. La poesía en los umbrales del Siglo Ilustrado», tiene su origen en el Coloquio Internacional «Sentiment et raison dans la poésie espagnole au Siècle des Lumières», celebrado en noviembre de 2014 en la Université Bordeaux Montaigne y organizado por el grupo de investigación AMERIBER junto con la Universidad de Córdoba. Este encuentro bordelés constituyó un fruto más de los cosechados en la larga y fecunda línea de investigación abierta por el añorado François Lopez y Nadine Ly con el coloquio «Penser la Littérature Espagnole», y proseguida en los magníficos trabajos reunidos en «La formation du Parnasse espagnol Xve-XvIIIe siècles», cuyas actas fueron publicadas en sendos volúmenes monográficos del Bulletin Hispanique (2004, 2007). 
Los comunicantes reunidos en Burdeos constituyen el núcleo central del proyecto de investigación dirigido por Pedro Ruiz Pérez «Poesía Hispánica en el Bajo Barroco (Repertorio, Edición, Historia)» (FFI2011-24102 del Plan Nacional de Investigación Científica, Desarrollo e Innovación Tecnológica), a su vez continuación del proyecto «La poesía del período postbarroco: repertorio y categorías» (FFI2008-03415/FILO del Plan Nacional de Investigación). Ambos proyectos han permitido la elaboración de la base Рнево (Poesía Hispánica en el Bajo Barroco, en línea en http://www.uco.es/phebo), así como la ampliación de la base de datos NICANTO ${ }^{1}$ a los impresos y anuncios de poesía en el período 1650-1750.

Los trabajos de nuestro monográfico, sometidos como todos los de la revista al habitual proceso de revisión por pares, podrían organizarse en torno a tres momentos, que conforman otras tantas etapas de la evolución de la poesía hispánica desde la segunda mitad del siglo XvII hasta el inicio de la poesía de la Ilustración.

Una primera serie de trabajos, centrada en la época de los novatores (16751725), se abre con el estudio de Elena Cano Turrión «Retóricas paratextuales académicas entre dos siglos. El entorno zaragozano», que pasa revista a los paratextos de un amplio corpus de libros de poesía del bajo Barroco impresos en la órbita zaragozana desde mediados del siglo XVII hasta las primeras décadas del XVIII, deteniéndose en la tipología característica de cada uno de los diferentes modelos textuales — aprobaciones, dedicatorias y prólogos, redactados por autores, libreros, impresores, aficionados o amigos del poeta- hasta abstraer un perfil de los usos retóricos establecidos por la práctica literaria. Cano Turrión atiende en especial a la transformación de los paratextos desde el alto Barroco, demostrando cómo los cambios en las retóricas paratextuales del bajo Barroco desvelan un cambio poético y metapoético bien perceptible para los mismos poetas y los responsables del proceso editorial. Por su parte, el trabajo de Antonio Sánchez Jiménez, «La musa casera: poesía de circunstancias y estética bajobarroca en el Ramillete poético de las discretas flores (1706) de José Tafalla Negrete», prolonga el estudio de Cano Turrión al centrase en los preliminares al Ramillete poético. Pone de relieve Sánchez Jiménez la ambigua reacción de los editores de Tafalla ante la posición de la poesía en la sociedad del bajo Barroco. El «discreteo», una de las características estéticas del momento —en que predominan prosaísmo, oralidad, circunstancialidad y tono y temática

1 Para una visión de conjunto de la base NICANTO, puede consultarse Jean-Marc BuIGuìs, «Indexación y códigos en bases de datos bibliográficas», Janus. Estudios sobre el Siglo de Oro, Anexo 1 (2014), págs. 123-135, en línea en http://www.janusdigital.es/anexos/contribucion.htm?id=12. 
distendidos-, fue consecuencia del nuevo papel que a la sazón desempeña la poesía, que pasa a dinamizar las reuniones informales. Imprimir unos textos de marcado sesgo oral fue percibido por los prologuistas como un problema, porque alteraba esencialmente la función de los poemas de Tafalla. El tercer estudio de esta primera serie, «Razones poéticas en los umbrales de la Ilustración temprana. Desde los Fragmentos del ocio», es obra de Pedro Ruiz Pérez, quien estudia los Fragmentos del ocio (1668, reeditado en 1683), atribuidos a Juan Gaspar Enríquez de Cabrera, apoyándose en un análisis cronológico de las ocurrencias de la palabra razón en el CordE en el periodo 1651-1685. Se detiene Ruiz Pérez en los ingredientes que van modulando la poética bajobarroca hasta prefigurar una estética que empieza a mirar hacia el Siglo de las Luces, en particular en lo referido a la reordenación de las relaciones entre sentimiento y razón, hasta culminar en una poesía que Ruiz Pérez singulariza por su estilo «razonable», su «musa sensata» y su carácter refractario a las estridencias, incluidas las de lo sublime. En el estudio de Carlos M. Collantes Sánchez, «Versos y tratados en la Ilustración científica (1650-1750)», que cerraría este primer grupo, se analizan los paratextos poéticos impresos en los libros de tema científico publicados en la España de entre siglos, especialmente en las obras de los novatores. El estudio cuantitativo y cualitativo de aquellos versos, tanto paratextuales como intratextuales, que novatores e impresores tenían a bien plasmar en sus obras permite comprender la función y finalidad de dichos poemas, ver si responden a las prácticas editoriales que se asentaron en la centuria anterior y analizar la relación entre los tratados de la nueva ciencia española y la poesía que en ellos se insertaba.

La segunda serie de trabajos de nuestro monográfico la constituyen dos artículos que analizan distintos poemas de Benito Jerónimo Feijoo y de Diego Torres Villarroel redactados en los años 20 y 30 del siglo XVIII, justo antes de la aparición de la Poética de Luzán (1737), pero publicados en su inmensa mayoría a partir de 1738. Rodrigo Olay Valdés, en «Nuevos datos sobre el Desengaño y conversión de un pecador de Benito Jerónimo Feijoo: datación, transmisión, fuente y máscara autorial», ofrece información desconocida que permite datar con precisión el más ambicioso y extenso de los poemas de Feijoo, el Desengaño y conversión de un pecador, toda vez que reconstruye su historia textual, identifica su fuente principal —el «Romance místico» de Eugenio Gerardo Lobo-y discute las implicaciones de la máscara autorial empleada por Feijoo para firmar su texto («Jerónimo Montenegro»). También realza Olay Valdés la importancia de Feijoo como poeta y la amplia difusión de su poesía — ciñéndonos al Desengaño, hay noticias de hasta dieciséis ediciones del poema solo en el siglo XVIII, manuscritos al margen-, a la par que señala que los dos únicos 
poemas que Feijoo decidió publicar pertenecen al género de la «poesía moral o metafísica», sin perder de vista que en ellos puede advertirse un alto componente retórico y literaturizado, lo que minoraba cualquier impúdica o primaria implicación afectiva, todo ello con vistas a no comprometer Fejoo con sus versos su imagen de religioso y ensayista de prestigio. Por su lado, el título del estudio de Ignacio García Aguilar, «El destierro de la sentimentalidad lírica aurisecular en los sonetos amorosos de Torres Villarroel», subraya los cambios que ya se afirman con más nitidez en la poesía que cierra la época de los novatores; en particular, una transformación que apunta hacia una mayor preponderancia de lo (entendido como) racional frente a la idealizada naturaleza de la protagonista femenina de la tradición previa. El análisis de García Aguilar, basado en los sonetos torresianos, muestra cómo la mujer no es ya un objeto idealizado e intangible (o intocable), sino, fundamentalmente, un sujeto histórico y palpable, signo en sí mismo de una nueva razón. La lectura de García Aguilar de la poesía de Torres a la luz de dos textos de Feijoo — «Causas del amor» y «Remedios del amor», del volumen séptimo del Teatro crítico universal - le permite establecer que este cambio en la relación amorosa poetizada «tiene mucho de curación racional, al modo en que plantea Feijoo sus "Remedios del amor", que no son sino un Ars amandi adecuado a los sujetos de un mundo en el que la razón domeña y gobierna al corazón».

Por fin, dos estudios conciernen a la última etapa en que aún pueden dejarse oír los últimos ecos de la poesía del bajo Barroco (1750-1767). El de JeanMarc Buiguès, «La razón de la enseñanza. La poesía en los colegios jesuitas del siglo XVIII: pedagogía y bibliotecas (1758-1767)», analiza las Prácticas e industrias para promover las Letras Humanas del P. Francisco Javier Idiáquez, una guía para la enseñanza del latín y del griego en los colegios de jesuitas publicada en 1758. Buiguès se centra en determinar qué lugar ocupa la poesía en el currículo de la educación jesuítica (horario, niveles, tipo de ejercicios pedagógicos, obras y manuales), a la par que intenta ver qué evoluciones al respecto ofrecen las Prácticas de Idiáquez en relación a la Ratio atque Institutio Studiorum Societatis Iesu, de 1598, y al Arte de Nebrija, en la versión del P. Juan de la Cerda. También establece Buiguès las listas de obras de poesía de los inventarios de las bibliotecas de los Colegios de jesuitas de Murcia y Medina del Campo, redactados a raíz de la expulsión (1767), y estudia los libros de poesía presentes en ellos a la luz de la nacionalidad de los autores, de las épocas de redacción y publicación de tales libros y de los distintos cánones poéticos en debate a mediados del siglo XVIII en España, comparando el corpus de obras aconsejadas por las Prácticas con el abanico de libros de poesía que ofrecían las bibliotecas jesuíticas y cotejando la teoría y la práctica de la enseñanza de 
la poesía con las posibles lecturas de poemas que ofrecían las bibliotecas. El segundo trabajo de esta última serie lo ofrece Ana Isabel Martín Puya con su texto «Azara corrige a Garcilaso: sentimiento y razón», que se basa en el análisis de las notas y del prólogo que redactó Nicolás de Azara para su edición de las Obras de Garcilaso (1765), tomando como punto de partida la idea de que Ilustración y Neoclasicismo «hallan en el término razón una de sus más firmes bases. La razón se convierte en norma y aspiración para buena parte de los intelectuales dieciochescos, haciéndose visible como ideal en obras de muy diversa índole. El sentimiento, por su parte, ha de ser pasado por el tamiz de la razón». Esta racionalidad ilustrada matiza la recepción de un «dolorido sentir» garcilasiano asumido ya universalmente como modelo clásico y digno de estudio. Las notas y el prólogo, pero también las variantes al texto garcilasiano, reflejan, en conjunto, la actitud intervencionista de Azara ante el texto de Garcilaso, así como su predilección por lo racional frente a lo sentimental.

Si los estudios reunidos en este monográfico no se circunscriben ni a la mera problemática definida por «Sentimiento y razón», ni tampoco a la "poesía en los umbrales del Siglo Ilustrado», es por la sencilla razón de que es imposible entender la producción poética del bajo Barroco sin situarla en una perspectiva más amplia —desde mediados del siglo XVII hasta avanzado ya el XVIII- que englobe el estudio no solo de los poemas sino también de sus paratextos, a la par que relacione dicha poesía con la aparición de corrientes científicas renovadoras, con las reflexiones teórico-religiosas en torno al sentimiento amoroso, con la transformación de los estudios de las Humanidades o con una evolución del estatus del poeta en su contexto editorial y social. 